\section{Bloodstream Infections Due to Micrococcus spp and Intravenous Epoprostenol}

To the Editor-We read with interest the article by Kallen et al $^{1}$ published in the April 2008 issue of the journal. Kallen et al presented a retrospective cohort study of bloodstream infection (BSI) in patients treated with intravenous prostanoids. The authors concluded that BSI due to gram-negative pathogens was more common in patients who received treatment with intravenous treprostinil than among patients who received treatment with intravenous epoprostenol. The authors reported the organisms that were isolated in blood samples from both groups. We believe that it is important to further examine these results.

Although the novel finding in this report was the higher rate of BSI due to gram-negative pathogens among patients treated with intravenous prostanoids, the authors did not comment on the high rate of BSI due to Micrococcus spp in patients treated with epoprostenol. In the latter group, micrococci were the second most common type of bacterium isolated (11 cases); in contrast, micrococci were isolated in none of the patients who received intravenous treprostinil. Micrococcus spp have been reported consistently as the second most common etiologic agent of BSI in patients receiving epoprostenol after Staphylococcus spp ${ }^{2-4}$.

In January 2008, we submitted a paper reporting the common occurrence of BSI due to Micrococcus spp among patients treated with intravenous epoprostenol at our institution. ${ }^{5}$ During the period from January 2001 to December 2006,45 cases of BSI occurred in patients who received intravenous epoprostenol through a Groshong catheter. There were 13 cases of BSI due to Staphylococcus aureus, 8 cases of BSI due to Staphylococcus epidermidis, and 5 cases of BSI due to Micrococcus spp. Because no patients at our institution were being treated with intravenous treprostinil at that time, we reviewed the blood culture results from 657 patients who were using a Groshong catheter during the same period for reasons other than pulmonary hypertension. Strikingly, we did not find any micrococcal BSIs in this group of patients.

Why are cases of BSI due to Micrococcus spp more frequent in patients treated with intravenous epoprostenol, whereas they are almost nonexistent in other groups with long-term central venous catheters, including patients who are treated with intravenous treprostinil? This question may have interesting answers. Maybe epoprostenol creates the right environment for the growth of micrococci during the preparation, storage, or delivery of the drug. But the most intriguing avenue for investigation, as we also suggested, is to explore the role of the prostanoids in modulation of the immune response in vivo as has already been demonstrated in vitro. ${ }^{6}$ The answer to our question may have implications for the development of new types of therapy for pulmonary hypertension.

\section{ACKNOWLEDGMENTS}

Potential conflicts of interest. All authors report no conflicts of interest relevant to this article.

Martin A. Valdivia-Arenas, MD

From the Department of Internal Medicine, Blanchard Valley Health System, Findlay, Ohio

Address reprint requests to Martin A. Valdivia-Arenas, MD, Department of Internal Medicine, Blanchard Valley Health System, 1900 South Main Street, Findlay, OH 45840 (martin1990jbr@yahoo.com).

Infect Control Hosp Epidemiol 2009; 30:1237

(C) 2009 by The Society for Healthcare Epidemiology of America. All rights reserved. 0899-823X/2009/3012-0019\$15.00. DOI: $10.1086 / 648663$

\section{REFERENCES}

1. Kallen AJ, Lederman E, Balaji A, et al. Bloodstream infections in patients given treatment with intravenous prostanoids. Infect Control Hosp Epidemiol 2008; 29:342-349.

2. Ehrensing ER, Stamm AM, Aaron MF, Bourge RC. Micrococcal bacteremia in patients with primary pulmonary hypertension on epoprostenol. In: Program and Abstracts, 8th Annual Meeting of the Society for Healthcare Epidemiology of America. Arlington, VA: Society for Healthcare Epidemiology of America; 1998. Abstract 94.

3. Oudiz RJ, Widlitz A, Beckmann XJ, et al. Micrococcus-associated central venous catheter infection in patients with pulmonary arterial hypertension. Chest 2004; 126:90-94.

4. Yap RL, Mermel LA. Micrococcus infection in patients receiving epoprostenol by continuous infusion. Eur J Clin Microbiol Infect Dis 2003; 22: 704-705.

5. Valdivia-Arenas MA, Sood N. Micrococcus bloodstream infection in patients with pulmonary hypertension on epoprostenol. Infict Dis Clin Pract 2008; 16:285-287.

6. Aronoff DM, Peres $\mathrm{CM}$, Serezani $\mathrm{CH}$, et al. Synthetic prostacyclin analogs differentially regulate macrophage function via distinct analog-receptor binding specificities. J Immunol 2007; 178:1628-1634.

\section{A Tertiary Care Cancer Center Experience of the 2007 Outbreak of Serratia marcescens Bloodstream Infection Due to Prefilled Syringes}

To the Editor-We read with great interest the article by $\mathrm{Su}$ et $\mathrm{al}^{1}$ that describes the 2007 outbreak of Serratia marcescens bloodstream infection in Texas due to contaminated prefilled heparin syringes. We had a similar outbreak at our institution ${ }^{2}$ during the same period, but interestingly the product incriminated in the investigation by Su et $\mathrm{al}^{l}$ was not being used at our institution. Even after the recall of all prefilled heparin syringes on December 20,2007, ${ }^{3}$ there were still new cases of $S$. marcescens bloodstream infection occurring among our patients with cancer, with some of these cases acquired nosocomially. The infection control team suspected a second 